\title{
MUSHROOMS OF GRAND TETON NATIONAL PARK
}

Kent H. McKnight

Plant Protection Institute, Agricultural Research Service

U.S. Department of Agriculture

Beitsville, Maryland

Kimbal T. Harper

Brigham Young University

Provo, Utah

and

Karl B. MCKnight

Department of Botany

University of Michigan

Ann Arbor, Michigan

\section{Objectives}

The recent checklist of macrofungi of Teton and Yellowstone Parks (McKnight 1982) provides a foundation on which to develop a more extensive floristic study. Collections of fungi and measurements of soil moisture were made in and around the Parks during the summer and early autumn of 1982 directed toward (1) adding to the number of species known to occur there; (2) comparing the mushroom species fruiting on 11 different forest stands over a 12-week period; and (3) elucidating possible correlations with mushroom fruiting and soil moisture.

\section{Methods}

The study stands were chosen to represent the diversity of forest types found in the Parks. A combination of other considerations, including accessibility, influenced site selection. Of the 11 sites, 5 are located within the boundaries of Grand Teton National Park; 3 are in Yellowstone National Park; 2 are in Jackson Hole near Grand Teton National Park; and 1 is on the west side of Teton Pass (Fig. 1). Tree species in forest stands located at Cattle Bridge (CAB), Nez Perce Creek (NEZ), and Signal Mountain (SIG) are predominantly Pinus contorta Dougl. (Lodgepole Pine) with some Populus angustifolia James (Narrowleaf Cottonwood) and occasional Picea pungens Engelm. (Blue Spruce) found at Cattle Bridge. Cottonwood in association with Blue Spnuce are the predominant trees at Snake Rivex Picnic Grounds (SNA) and Pacific Creek (PAC), whereas at Turpin Meadow (TOP) and Pilgrim Creek (PIL) sites some Cottonwood is mixed with Spruce, Pine, and Subalpine Fir (Abies lasiocarpa (Hook.) Nutt.). Some Douglas Fir (Pseudotsuga menziesii (Mirb.) Franco) trees are found at Turpine Meadow. The Eorest stands at Northeast Entrance (NEE) of Yellowstone National Park and West Side of Teton Pass (WES) contain a mixture of Spruce, Fir, and Pine with Douglas Fir occuncing abundantly at the West Side 
Figure 1. Geographical location of the 11 study stands. Park boundries are shown as solid lines ( - ) , and major highways as broken lines ( - - - ) .

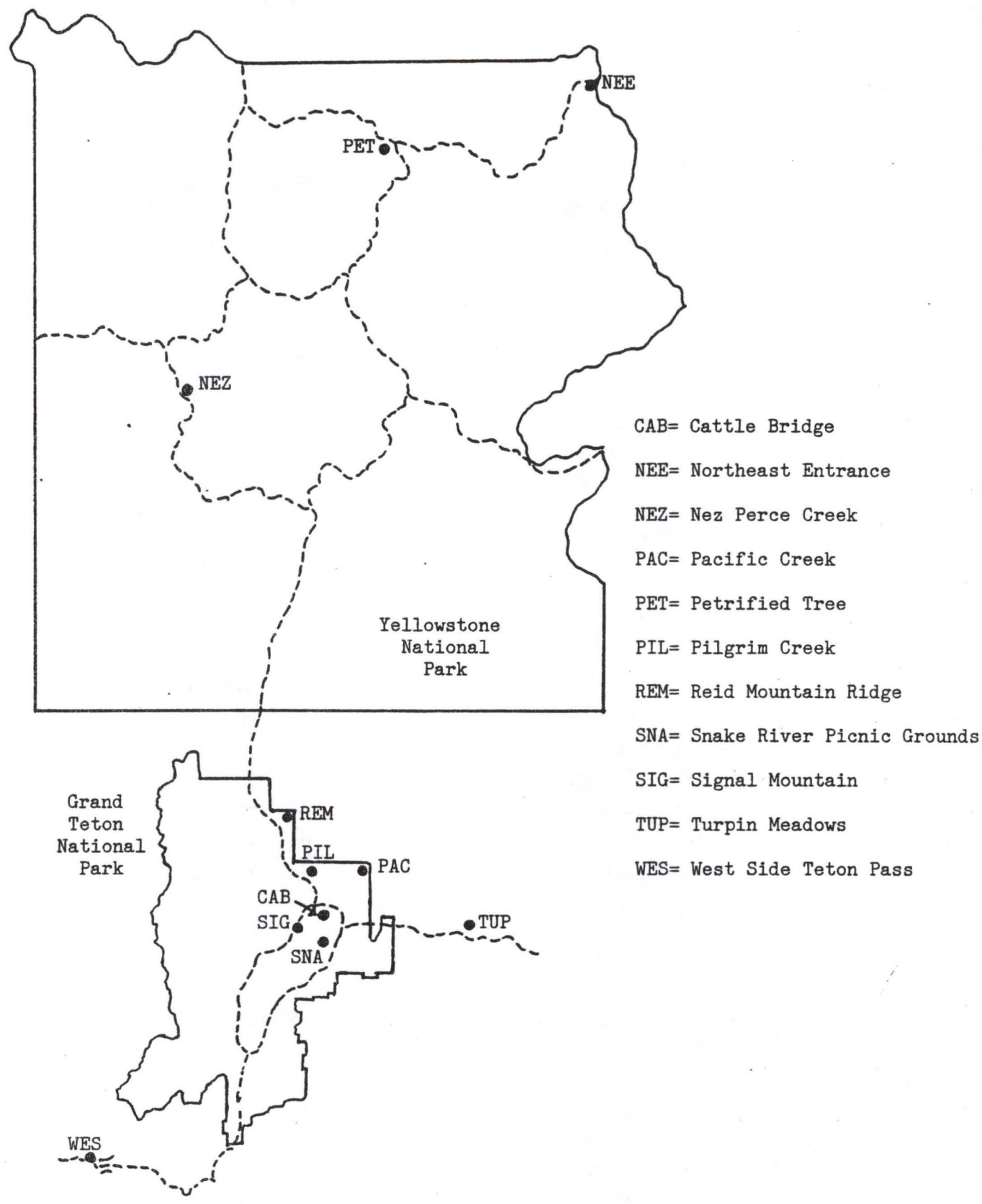


1ocation. Blue Spruce is the predominant tree species in the low, more or less Swanpy part of the forest stand studied at Petrified Tree (PET), whereas Douglas Fir predominates on the slope above. The site ai Reid Mtn. Ridge (REM) was located in a forest of Aspen (Populus tremuloides Michx.) with occasional scattered conifers.

Each study stand was visited weekly from 28 June through 12 September, 1982. An attempt was made to record presence of all fungus species fruiting at each site. Presence alone was noted for those species readily identified with accuracy in the fiela. For all others at least one collection of each species was brought to the field laboratory for identification. Dried herbarium specimens were prepared for at least one collection of each species recorded from each study stand. Esssiccatti are deposited at the National Fungus Collections (BPD. When the specimen is adeguate, replicates are prepared for the herbarium of the National Park Service in Yellowstone National Park (YELLO). Presence records and collection data were entered in computer files. From the presence records tables were compiled for each study site and patterns of phenological similarity in mushroom species were determined by statistical analysis.

Soll samples vere collected at three locations in each study stand weekly to determine soil moisture. At each location one sample was taken from the "O" horizon and one at a greater depth that gave a mixture of the " $\mathrm{A}$ " and " $\mathrm{B}$ " horizons. After oven drying for three days, soil moisture content was determined and concelated with the mushroom presence data for each site and with soil and vegetation parameters determined at two of the sites in the 1980 field season (Mcknight, Barpec, \& McKnight 1981).

\section{Data and Aralysis}

The late spring and relatively cool, wet weather throughout the growing season of 1982 influenced mushroom fruiting in two very significant ways: (I) many species apparently fruited 1 to 2 weeks later in the season than usual; and (2) this was an unusually productive mushroom season both in number of species and number of carpophores sighted. Over 2300 collections were processed at the field station for the herbarium. The following 62 taxa not previously reported (McKnight, loc. cit.) were identified and added to the list, making a total of 532 documented species and ssbspecific taxa with voucher specimens:

Amanita pachycolea Thiers \& A mmirati

A manita pantherina DC: Fr. var. velatipes (Atk.) Jenkins

Amylocystis lapponicus (Rom.) Bond. \& Singer

Boletus piperatus Fr.

Claudopus byssisedus (Pens: Gr.) Gill

Clavariadelphus borealis Wells \& Kempton

Claviadelphus lovejoyae Wells \& Kempton

Clavariadelphus Iigula $(F x$ ) Donk

Collybia maculata Bull. Fr. var, scorzonerea (Fr.) Gill

Conocybe tenera (Schaeff.: Fr.) Kuhn.

Coriolus abietinus (Dicksa) quel.

Coriolus subchartaceous Murril. 
Cortinarius bovinus Fr.

Cortinarius olympianus A. H. Smith

Cortinarius vanduzerensis A. H. Smith \& Trappe

Crepidotus payettensis A. H. Smith

Cryptoporus volvatus (Pk.) Hubbard

Cyathus striatus Pers.

Eccila byssisedus Pers.: Fr.

Galerina autumnalis (Pk.) A. H. Smith \& Sing.

Galerina unicolor (Fr.) Sing.

Geopora cooperi Harkn.

Gymnopilus liquiritae (Pers.) Karst.

Gymnopilus sapineus (Fr.) R. Maire

Hebeloma idahoense A. H. Smith ined.

Hebeloma velatum $\mathrm{Pk}$.

Hebeloma vinaceoumbrinum A. H. Smith ined.

Helvella griseoalba Weber

Helvella leucomeleana (Pers.) Nannf.

Hydnellum ferrugipes Coker

Hygrophoropsis aurantiaca (Fr.) R. Maire

Hygrophorus pusillus $\mathrm{Pk}$.

Iocybe lilacina (Boud.) Kauffm.

Lentinellus cochleatus (Fr.) Karst.

Limacella illinita (Fr.) Earle

Lyophyllum decastes (Fr.) Sing.

Marasmius thujinus $\mathrm{Pk}^{\mathrm{k}}$.

Melanoleuca brevipes (Fr.) Pat.

Melanoleuca microspora Gillm. \& O. K. Miller

Melanospora zobelii (Cda.) Fuckel

Morchella esculenta St. Amans: Pers. var. atrotomentosa Moser

Mycena epipterigera (Fr.) S. F. Gray

Mycena haematopus (Fr.) Kummer

Peziza fimeti (Fuckel) Seaver

Pholiota carbonaria A. H. Smith

Pholiota flammans (Fr.) Kumm.

Pholiota humii. A. H. Smith \& Hesl.

Pluteus pellitus (Fr.) Kumm.

Pluteus petasetus (Fr.) Gill.

Polyporus caesius Schrad.: Fr. = Leptoporus caesius (Schrad.: Fr.) Guel.

Psathyrella circellatipes Benoist

Psathyrella georgiana A. H. Smith

Psathyrella populorum Trueblood \& A. H. Smith

Psathyrella spadicea (Fr.) Sing.

Psathyrella subpurpurea A. H. Smith

Psathyrella weberi (Murr.) Sing.

Pseudohydnum gelatinosum (Scop.: Fr.) Karst.

Ramaria apiculata (Fr.) Donk

Ramaria botrytis (Fr.) Ricken

Ramaria ochraceovirens (Jungh.) Donk

Russula claroflava Grove

Stereum abietinum Fr.

Tricholoma sulphureum (Bull.: Fr.) Kumm. 
Trichophaea gregaria (Rehm) Boud.

Xeromphalina cauticinalis (Fr.) Kuhner \& Maire

Many more will be added to the list from the unidentified collections being processed at the National Fungus Collections. The collections and field sightings made this summer combined with those of previous years gives a total of 3,029 records for the 11 sites under intensive study.

Complete analysis and interpretation of the data collected thus far can not be accomplished prior to identification of all collections and completion of soil and plant community characterizations of the stands proposed for the field season of 1983. Because of this and the space constraints imposed on this report, the three localities at Nez Perce Creek (NEZ), Turpin Meadow (TUP) and West Side Teton Pass (WES) were selected as sample stands to be reported in more (but not complete) detail here.

Comparison of the species lists for the three sample stands showed 14 species that were readily identifiable in the field and which fruited at all three stands. Their phenological fruiting patterns are shown in Table 1. Phenological differences are evident for a number of species, some of the most interesting being Suillus tomentosus and the two species of Tricholoma. At Nez Perce Creek (NEZ) Suillus tomentosus was observed each week over an 8-week period from mid-July through early September whereas at Turpin Meadow (TUP) it was recorded only 5 times toward the latter part of this period and at west Side T'eton Pass (WES) only two occurrences were recorded. Tricholoma myomyces showed almost the reverse fruiting pattern with 9 occurrences over a 10-week period at TUP compared with 5 occurrences at WES and one at NEZ. Tricholoma saponaceum, on the other hand ${ }_{p}$ showed 5 weekly occurrences at both NEZ and TUP and 4 at WES, all widely scattered throughout the fruiting season at each site.

In pairwise comparisons of the phenological patterns of the macrofungal species on the three sample stands WES was intermediate with respect to TUP and NEZ. Species that were found at both NEZ and WES were found, on the average, 1.9 weeks later at WES ( $n=23)$. Species found both at WES and TUP were found 1.2 weeks later at TUP ( $n=39)$. Lastly, species in common to both NEZ and TUP were found 4.0 weeks later at TUP $(n=21)$.

The sampling methods used in collecting the soil and litter moistaure data of the 1982 field season permitted the estimation of four kinds of moisture variables for each stand: 1) the average moisture for the entire growing season; 2) the temporal variability of moisture throughout the growing season; 3) the average variability of moisture from point-to-point within the stand; and 4) the temporal variability of the point-to-point variability of moisture within the stand throughout the growing season. The four kinds of variables were estimated for both litter and soil. Percentage wet-weight was determined for three litter and three soil sub-samples taken from each stand, each week. Means and standard deviations were calculated weekly. Soil moisture measurements show that TUP was a comparatively wet stand; NEZ was a very dry stand; and WES was intermediate with respect to soil moisture (Table 2). 


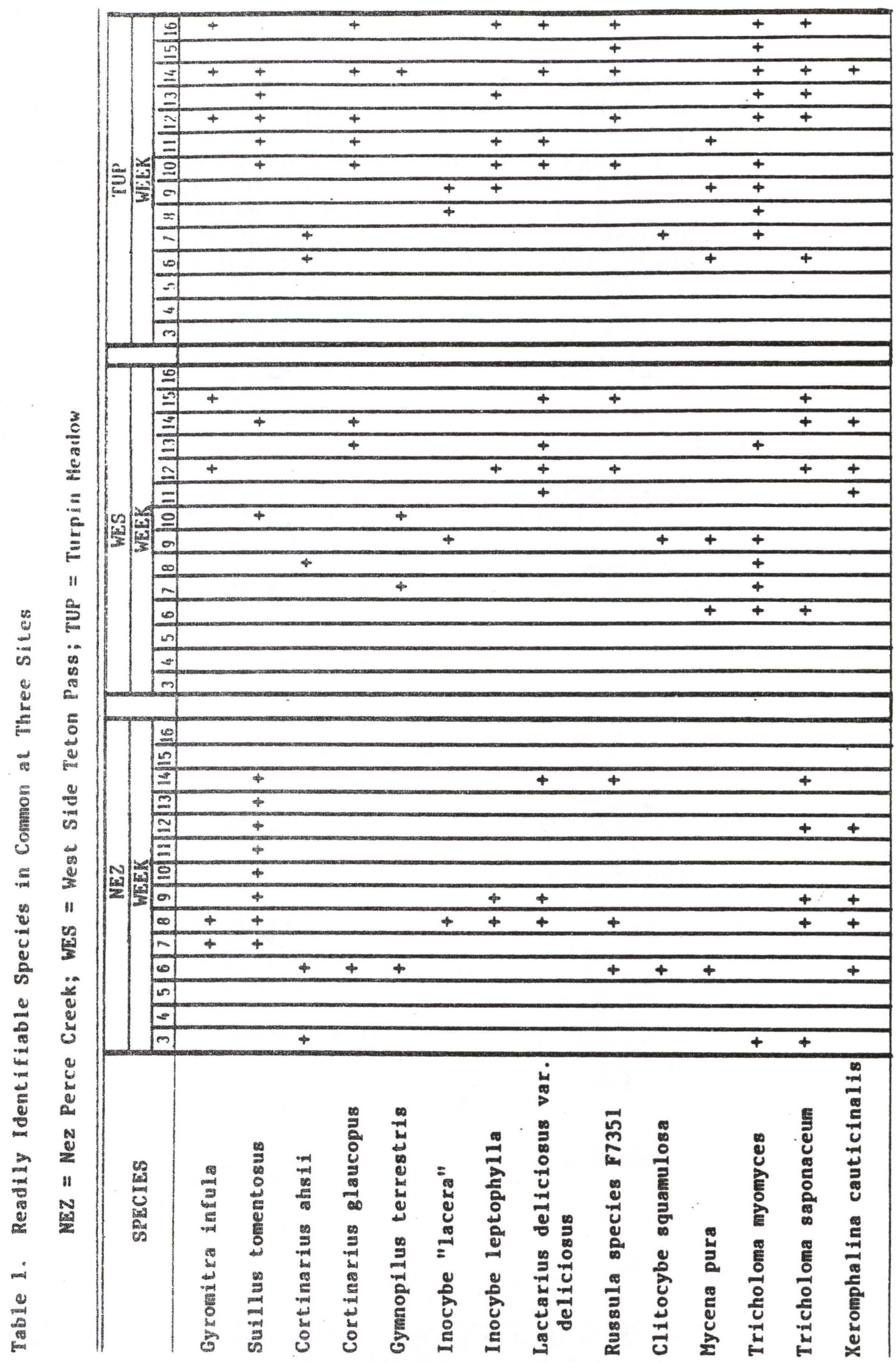


Table 2. Summary statistics of litter and soil moisture for the 11 stands during 10 weeks of the 1982 field season. The 10 weekly estimates of the mean and standard deviation were combined as follows: $\vec{X}(\bar{X})=$ average moisture for a stand for the entire growing season; $\sigma(\bar{X})=$ temporal variability of the moisture throughout the growing season; $\bar{X}(\sigma)=$ average variability of the moisture from point-to-point within the stand; and $\sigma(\sigma)=$ variability of the point-to-point variability of moisture within the stand.

\begin{tabular}{|c|c|c|c|c|c|c|c|c|}
\hline & & $\underline{\text { Litt }}$ & & & & Soil & & \\
\hline Study Stand & $\underline{\bar{x}(\bar{x})}$ & $\sigma(\bar{x})$ & $\overline{\underline{x}}(\sigma)$ & $\sigma(\sigma)$ & $\underline{\bar{x}(\bar{x})}$ & $\sigma(\bar{x})$ & $\underline{\bar{x}}-\underline{ }$ & $\sigma(\sigma)$ \\
\hline $\begin{array}{l}\text { Cattle Bridge } \\
\text { (CAB) }\end{array}$ & 23.16 & 12.60 & * & * & 12.59 & 6.75 & $*$ & $*$ \\
\hline $\begin{array}{l}\text { Northeast Entrar } \\
\text { (NEE) }\end{array}$ & $\begin{array}{l}\text { ince } \\
65.01\end{array}$ & 30.70 & 61.91 & 29.31 & 20.03 & 6.63 & 9.15 & 6.09 \\
\hline $\begin{array}{l}\text { Nez Perce Creek } \\
\text { (NEZ) }\end{array}$ & k1.16 & 10.16 & 9.31 & 3.78 & 12.21 & 5.79 & 6.50 & 3.43 \\
\hline $\begin{array}{l}\text { Pacific Creek } \\
\quad(P A C)\end{array}$ & 85.73 & 32.34 & 35.90 & 27.75 & 48.90 & 25.18 & 35.90 & 35.11 \\
\hline $\begin{array}{l}\text { Petrified Tree } \\
\text { (PET) }\end{array}$ & 126.33 & 40.54 & 76.80 & 64.64 & 65.62 & 49.83 & 67.14 & 84.78 \\
\hline $\begin{array}{l}\text { Pilgrim Creek } \\
\text { (PIL) }\end{array}$ & 73.92 & 22.26 & 34.12 & 25.04 & 29.07 & 15.41 & 12.33 & 21.05 \\
\hline $\begin{array}{l}\text { Reid Mountain } \\
\text { Ridge } \\
\text { (REM) }\end{array}$ & 76.46 & 31.96 & 27.66 & 10.58 & 29.22 & 12.31 & 9.28 & 8.07 \\
\hline $\begin{array}{l}\text { Snake River } \\
\text { Picnic Grounds } \\
\text { (SNA) }\end{array}$ & 59.52 & 20.04 & 38.21 & 21.23 & 36.54 & 7.26 & 29.03 & 8.95 \\
\hline $\begin{array}{l}\text { Signal Mountain } \\
\text { (SIG) }\end{array}$ & 46.02 & 30.64 & 21.85 & 24.19 & 16.18 & 3.90 & 5.93 & 3.91 \\
\hline $\begin{array}{l}\text { Turpin Meadow } \\
\text { (TUP) }\end{array}$ & 154.89 & 41.55 & 82.59 & 30.70 & 66.87 & 26.14 & 53.43 & 40.15 \\
\hline $\begin{array}{l}\text { West Side } \\
\text { Teton Pass } \\
\text { (WES) }\end{array}$ & 77.97 & 29.31 & 33,33 & 17.02 & 31.24 & 5.47 & 7.54 & 5.37 \\
\hline
\end{tabular}


The multivariate statistical technique of principal components was used to further summarize and visually display the soil and litter moisture data (Fig. 2). The first component accounted for $83.4 \%$ of the total variance in all eight moisture variables. All eight variables contributed approximately equally to the direction of the first component. These two results were not expected, inasmuch as all. eight moisture variables were positively correlated. The position of TUP, NEZ, and WES along the first component agrees with the finding above (Table 2) from soil moisture measurements that TUP is a very wet stand, NEZ is dry, and WES is intermediate. Future studies should determine how much of the stand moisture results from winter snowpack; how much from summer precipitation; and how much from drainage from other sources.

An additional $8.4 \%$ of the total variance in all eight original moisture variables was recovered by the second principal component. This new "summarizing variable" was closely aligned with the variance unaccounted for in the soil and litter variables describing the temporal variability of stand moisture throughout the growing season. This new variable was positively correlated with the coefficient of variation $(\mathrm{CV}=\sigma / \mathrm{X})$ of the 11 stands. The placement of TUP and $\mathrm{WS}$ along the second principal component indicates similarity of these two stands (Fig. 2) in that both stands had small amounts of variation with respect to the mean soil and litter moisture levels (low CV's). NEZ, on the other hand, is highly variable with respect to its soil moisture means (high CV).

Taken together, the finst two principal components account for $91.7 \%$ of the total variance found in the eight original moisture variables. This suggests that little was gained by calculating the point-to-point moisture variability and the temporal variability of the point-to-point variability. Consequently, the amount of moisture on a stand (litter or soil) and the temporal variability of that moisture are sufficient in evaluating moisture relationships.

The intermediate nature of WES with respect to TUP and NEZ was further borne out by many of the stand overstory and understory vegetation parameters and soil depth (Table 3). Pinus contorta comprised $8.2 \%$ of the total stand basal area at TUP, $32.6 \%$ at WES, and $100 \%$ at NEZ. The only other tree species that add significantiy to the total basal area at TUP was Picea englemanii (91.8\%). At WES, P. englemanii contributed 11.5\%, Pseudotsuga menzesii 15\%, and Abies lasiocarpa 40.9\%. WES was also intermediate between TUP and NEZ for average basal area/tree, of overstory cover, soil depth, understory vegetation height, of of living cover that was forbs, and 8 of living cover that was grasses. WES had values closer to TUP than NEZ for number of trees/hectare, of cover that was

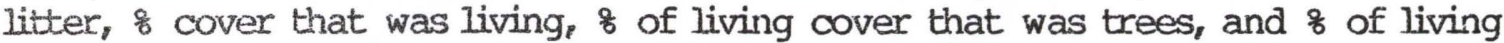
cover that was shrubs. However, NEZ was more similar to TuP with respect to total basal area/hectare, \& cover that was rock, 8 cover that was soil, and 8 of living cover that was cryptogams.

Given such a high similarity between WES and TUP for so many understory and overstory parameters and soil depth, and given the intermediate nature of WES (between TUP and NEZ) with respect to soil and litter moisture, it was not surprising that the fungus flora also at WES suggests a pattern of similarity intermediate in the three stands. We have collected 160 mushroom species at TUP, 124 species at WES and 88 at NEZ. West Side of Teton Pass (WES) was 
Figure 2. Principal components ordination of the 11 stands using eight normalized moisture variables for each stand. The first component (horizontal axis) accounted for $83.4 \%$ of the total variance of ali the eight variables and the second component (vertical axis) recovered an additional $8.3 \%$ of the total variance. For each stand four variables were measured for both the litter and soi!: 1) the average moisture for the entire growing season, 2) the variability of the moisture throughout the growing season, 3) the average variability of the moisture within the stand, and 4) the variability of the variability of the moisture within the stand. It is important to note that since all 8 variable were so highly, positively correlated, the variable loadings for the first components were all approximately equal. The second component was more closely aligned with the two variables describing the variability of the soil and litter moisture throughout the growing season.

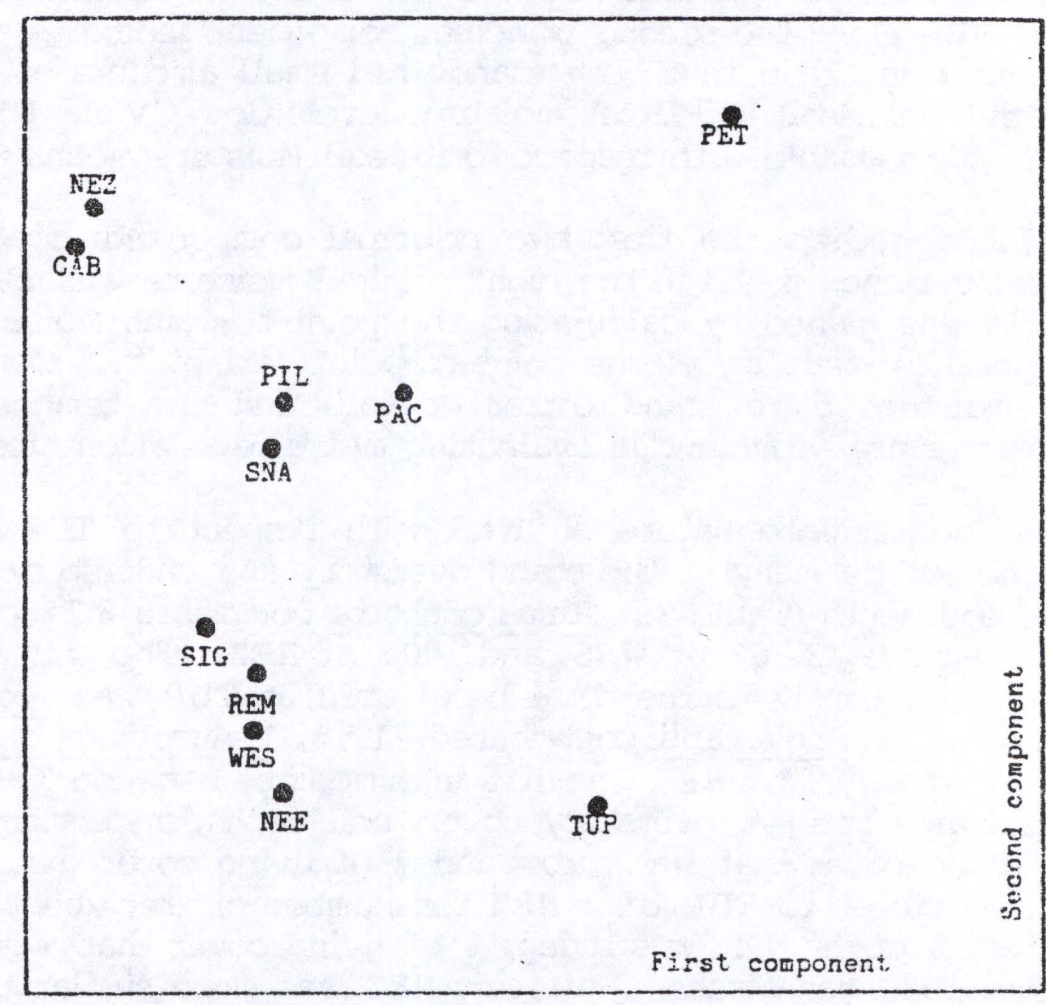

$C A B=$ Cattle Bridge

NEE $=$ Northeast Entrance

NEZ = Nez Perce Creek

$P A C=$ Pacific Creek

PET = Petrified Tree

$P I L=$ Pilgrim Creak
REM = Reid Mountain Rijge

SNA = Snake River Picnic Gr.

SIG = Signal Mountain

TUP = Turpin Meadow

WES $=$ West Side Teton Fass 


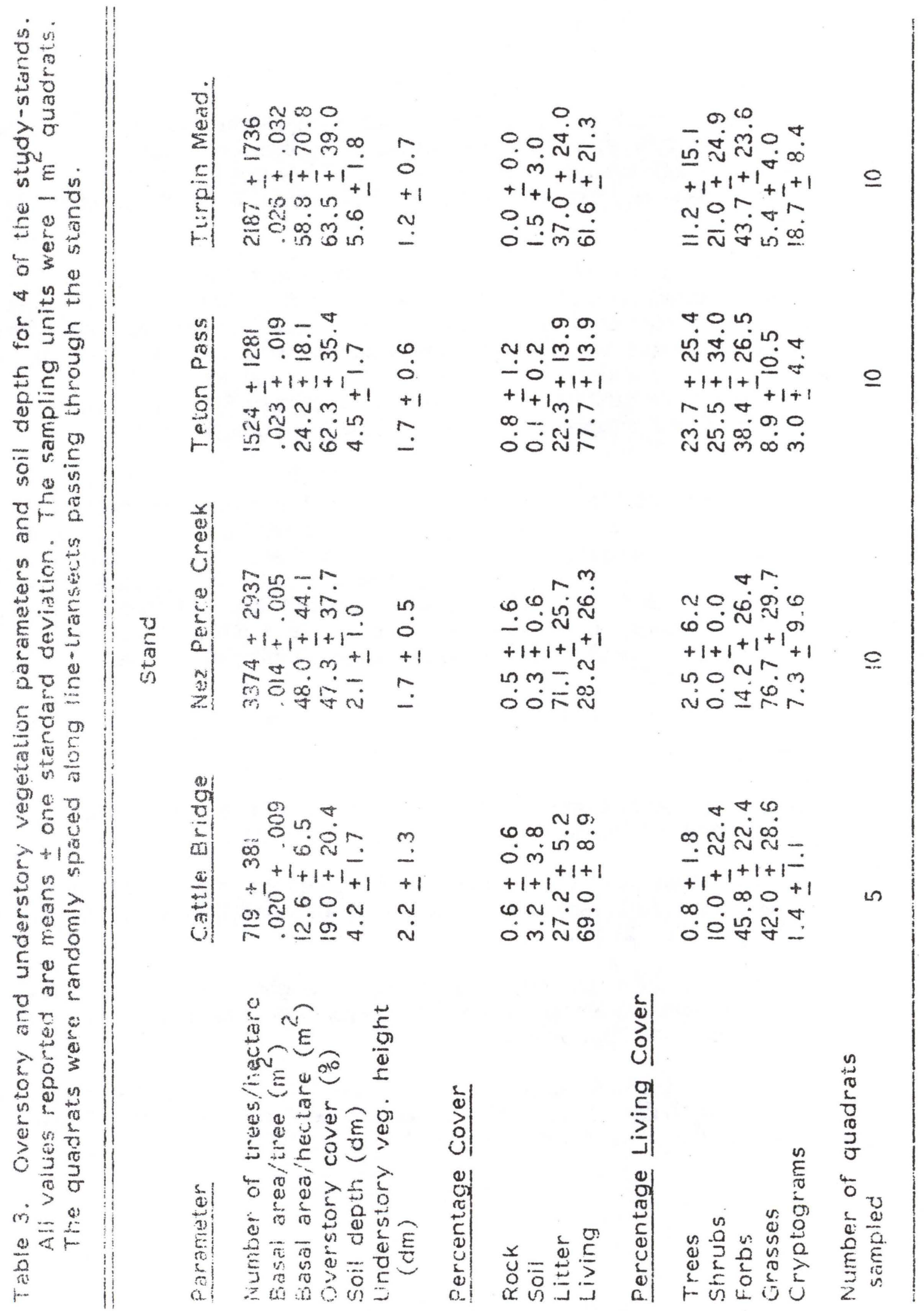


also intermediate between TUP and NEZ with respect to species similarity ( 8 Similarity $=2 C / A+B$ ) where $A=$ number of species on one stand; $B=$ number of species on another stand; and $C=$ number of species in com mon to both stands). WES was $33 \%$ similar to TUP and $25 \%$ similar to NEZ. NEZ was only $22 \%$ similar to TUP.

Using a two-dimensional polar-ordination (Bray and Curtis, 1957) of macrofungal species composition REM was the stand most dissimilar to all the other stands. NEZ was the most dissimilar stand to REM. Hence, these two stands formed the opposite endpoints for the first axis (Fig. 3). TUP and WES were intermediate with respect to these two endpoints. The second axis had CAB and SNA as endpoints. Here NEZ was much closer to CAB than SNA, whereas the other two members of our sample triad, TUP and WES, were more similar to SNA than CAB.

We have not yet attempted to correlate soil moisture, vegetation parameters and soil depth, macrofungal species composition, or macrofungal species phenology. The preliminary patterns we have seen by superficially examining just three stands, TUP, WES, NEZ, suggest that the comparisons within and between these four kinds of data will be profitable. The additional mushroom collecting, vegetation sampling, soil moisture and pH measurements planned for summer of 1983 will make possible more meaningful comparisons for all 11 stands.

\section{Literature Cited}

Bray, J. R. \& J. T. Curtis. 1957. An ordination of the upland forest com munities of southern Wisconsin. Ecol. Monogr, 27:325-349.

McKnight, Kent H. 1982. Checklist of Mushrooms and Other Fungi of Grand Teton and Yellowstone National Parks. Univ. of Wyo.-NPS Research Center, Moran, WY. 21 pp.

McKnight, K. H., K. T. Harper, \& K. B. McKnight. 1981. Mushrooms of Grand Teton National Park, in Univ. of Wyo.-NPS Research Center 4th Annual Report, 1980. pp. 58-61.

Sorenson, T. 1948. A method of establishing groups of equal amplitude in plant sociology based on similarity of species content. Det. Kong. Danske Vidensk. Selsk. Biol. Skr. (Copenhagen) 5(4):1-34. 
Figure 3. Polar ordination (Bray \& Curtis, 1957) of the II study stands grouped with respect to $\%$ similarity of mushroom species. Mushroom species lists from the 11 stands were combined in pairwise comparisons of \% similarity using Sorensen's (1948) formula: Similarity $=\frac{2 C}{A+B}$ when $A=$ number of species on the first stand; $B=$ number of species on the second stand; and $\mathrm{C}=$ number of species in common to both stands.

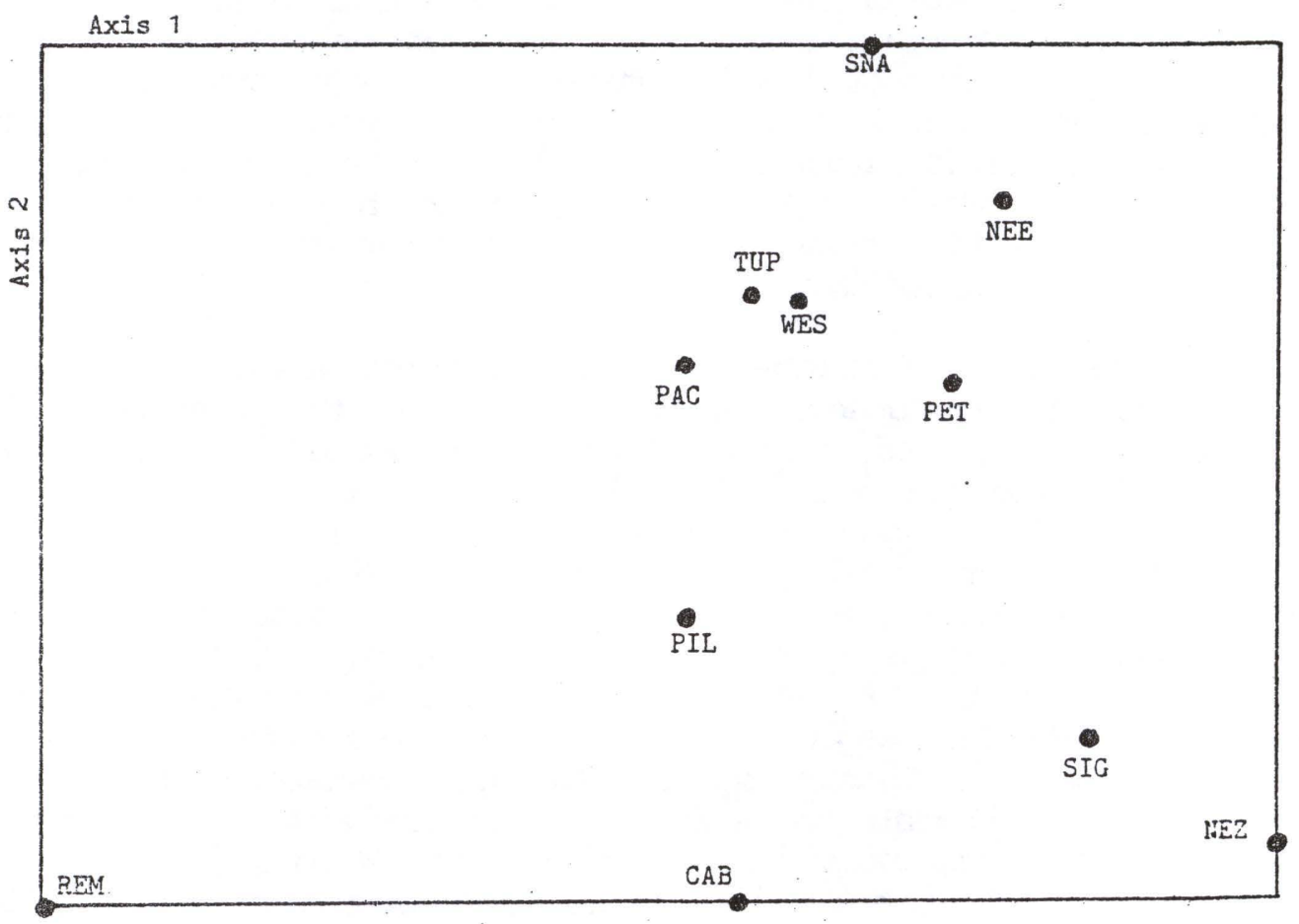

$C A B=$ Cattle Bridge

NEE = Northeast Entrance

$N E Z=$ Nez Perce Creek

PAC = Pacific Creek

PET = Petrified Tree

PIL = Pilgrim Creek
REM = Reid Mountain Ridge

SNA = Snake River Picnic Gr.

SIG = Signal Mountain

TUP = Turpin Meadow

WES $=$ West Side Teton Pass 